
\section{International Scientific Journal Theoretical \& Applied Science}

\author{
p-ISSN: 2308-4944 (print) e-ISSN: 2409-0085 (online) \\ Year: 2017 Issue: 08 Volume: 52
}

Published: $30.08 .2017 \quad$ http://T-Science.org
Vladimir Nikolaevich Medvedev

The Teacher Department of Navigation,

The Engineer-mechanic,

State Maritime University Admiral Ushakov, Russia, medvedevsail@gmail.com

SECTION 21. Pedagogy. Psychology. Innovation in Education

\title{
YACHTING - DEVELOPMENT OF THE GENERALIZED PROFESSIONAL ACTIVITY OF STUDENTS
}

\begin{abstract}
The basic principles of building an educational system of students engaged in yachting are considered; reveals the increasing role of students in yachting in the system of maritime vocational education and the lack of development of their practical organizations; analysis of the need for modern society in students with highly developed professional qualities and insufficient use of educational opportunities for yachting; shows the need to develop the professional qualities of students and the insufficiently developed scientific and methodological support of the basics of practical yachting.

Key words: forming of the personality, students, yachting, professional education, practical organization, naval fleet.

Language: Russian

Citation: Medvedev VN (2017) YACHTING - DEVELOPMENT OF THE GENERALIZED PROFESSIONAL ACTIVITY OF STUDENTS. ISJ Theoretical \& Applied Science, 08 (52): 108-114.

Soi: http://s-o-i.org/1.1/TAS-08-52-17 Doi: crossef https://dx.doi.org/10.15863/TAS.2017.08.52.17
\end{abstract}

УДК 372.851

\section{ЯХТИНГ - ПРОЦЕСС РАЗВИТИЯ ОБОБЩЁННОЙ ПРОФЕССИОНАЛЬНОЙ ДЕЯТЕЛЬНОСТИ СТУДЕНТОВ}

Аннотация: Рассмотрены основные принципь построения воспитательной системьл студентов, занимающихся яхтингом; раскрывается возрастающая роль занятий студентов яхтингом в системе морского профессионального образования и недостаточная разработанность их практических организаций; анализируется потребность современного общества в студентах с высокоразвитыми профессиональными качествами и недостаточное использовании воспитательных возможностей занятий яхтингом; показывается необходимость развития профессиональных качеств студентов и недостаточная разработанность научно-методического обеспечения основ практических занятий яхтингом.

Ключевые слова: формирование личности, студенты, яхтинг, профессиональное образование, практическая организачия, морской флот.

\section{Introduction}

Обществу нужны специалисты, готовые к самостоятельному включению в производственные процессы, способные практически решать встающие перед ними жизненные и профессиональные задачи. А это во многом зависит не только от полученных знаний, умений, навыков, но и от дополнительных качеств, для обозначения которых в настоящее время и употребляются понятия «компетенция» и «компетентность», более соответствующие требованиям, предъявляемым в реальных условиях работодателями. В учебных заведениях реализуется традиционная модель обучения, основанная на знаниевой парадигме образования, переход на компетентностный подход в системе образования требует обновления содержательно-технологического обеспечения учебно-воспитательного процесса.

Таким образом, формирование востребованных современным рынком труда профессиональных компетенций у студентов является актуальной образовательной задачей, что подтверждается тем, что именно 
компетентностный подход заложен сегодня в основу нового федерального государственного образовательного стандарта (ФГОС).

Формирование

обобщённой профессиональной деятельности студента процесс, в ходе которого он приобретает профессионально важные знания, навыки, качества. Условием успешного формирования обобщённой профессиональной деятельности студента является его положительное отношение к учебе, установленным порядкам в вузе, научно оправданная организация его деятельности, выполнение задач, упражнений, создание обстановки для наиболее интенсивного проявления и совершенствования профессионально важных знаний, навыков, умений, психических процессов, личных качеств. Обобщенно можно выделить три группы психологических условий успешного формирования профессиональной деятельности студента в вузе: со стороны студентов; со стороны преподавателей, руководителей; со стороны их совместной деятельности. Студента как личность формирует вся сумма влияний, которым он подвергается: организация учебы, занятия по различным предметам, личный пример преподавателя, руководителя, отношение товарищей. Будучи взаимно связанными, все качества формируются в органическом единстве. $[9,1]$.

Непрерывное самообразование, повышение профессиональной компетентности студентов, независимо от уровня получаемого образования, выступают как метод сопровождения их деловой карьеры, как способ творческой самореализации. Для общества непрерывное совершенствование профкомпетентности студент ов становится механизмом воспроизводства и развития рабочей силы, также ориентированной на непрерывное расширение «горизонтали» своей квалификации, возможности которого безграничны.

В последнее время ведется активный поиск способов и средств подготовки специалистов нового поколения практически по всем специальностям высшего профессионального образования, обладающих необходимыми личностно-профессиональными качествами. Однако опыт работы в профессиональном образовании показывает, что развитие таких качеств не является приоритетной задачей высших учебных заведений, а происходит стихийно. Ключевой проблемой современной высшей школы является личностное и профессиональное развитие студента, его самоопределение в профессии, поиск и нахождение смысла своего профессионального бытия, отношение к истине, которые воплощаются в практической деятельности.
Проблема обобщённого профессионального развития будущих специалистов весьма актуальна в условиях модернизации системы высшего профессионального образования.

Развитие профессиональной компетентности студента в гуманистическом пространстве личностно ориентированного подхода дает возможность преподавателям и студентам искать и находить такие отношения, которые стимулируют расширение сферы сознания, способствуют повышению мотивации образования с целью приобретения в профессиональной деятельности собственного индивидуального смысла.

Несмотря на достаточно широкий спектр исследований, посвященных поиску наиболее эффективных способов психологопедагогических ресурсов развития обобщённой профессиональной деятельности студентов, ученые не рассматривали в качестве одного из них студенческий яхтинг как вид факультативной деятельности в вузе.

\section{Materials and Methods}

Яхтинг можно рассматривать как важный психолого-педагогический ресурс для приобретения студентами определенного жизненного и практического опыта, создания инновационно-творческой образовательной среды, усиления профессиональной мотивации, овладения способами

самоуправления и самообразования, создания атмосферы сотрудничества, а также воспитания профессионально значимых качеств: умение работать в коллективе, где важно понимание «чувства локтя»; уметь подчиняться и руководить коллективом в разных обстоятельствах; а также системного восприятия будущей профессиональной деятельности, которое способствует развитию мотивации углубления знаний в профессиональной деятельности.

Анализ научной литературы и социальнопедагогической работы современных образовательных учреждений позволил выявить следующие противоречия: между постоянно растущими требованиями социума к личностнопрофессиональному уровню студентов специалистов и их традиционной подготовкой, ориентированной развитие предметных компетенций данной отрасли; между необходимостью приобретения студентами - специалистами таких качеств, как умение работать в коллективе, уметь подчиняться и руководить коллективом в разных обстоятельствах, а также системного восприятия будущей профессиональной деятельности и их ограниченным использованием в профессиональной подготовке, которые являются 
психолого-педагогическим

ресурсом

для развития личности.

Выявленные противоречия позволяют сформулировать проблему в виде следующего вопроса: при каких психолого-педагогических условиях яхтинг может быть ресурсом развития обобщённой профессиональной деятельности будущего специалиста?

Актуальность проблемы определила тему исследования «яхтинг - процесс развития обобщённой профессиональной деятельности студентов».

Объект исследования: профессиональная подготовка специалистов в высшей школе.

Предмет исследования: занятия яхтингом в вузе как ресурс развития обобщённой профессиональной деятельности будущих студентов - специалистов.

Цель исследования состоит в теоретическом обосновании и экспериментальной проверке эффективности модели занятий яхтингом для развития обобщённой профессиональной деятельности будущих студентов - специалистов.

Задачи исследования:

1.Обосновать методологическую ценность антропологического, аксиологического и деятельностного подходов для исследования и организации занятий яхтингом в вузе;

2. Раскрыть сущность учебнопрофессиональной деятельности студентов;

3. Раскрыть понятие «занятия яхтингом в вузе» с точки зрения его значимости для студентов и определить условия, позволяющие ему быть ресурсом для «запуска» психологических механизмов личностного развития профессиональной деятельности будущих студентов - специалистов;

4. Разработать модель занятий яхтингом в вузе и экспериментально проверить эффективность влияния предлагаемой модели на развитие профессиональной деятельности будущих студентов - специалистов;

5. Выявить основные тенденции развития учебно-профессиональной деятельности студентов ВУЗов высшего профессионального образования (ВПО).

Для решения поставленный задач и проверки гипотетических положений применялись методы: теоретико-педагогический анализ (историографический, системный, логический, моделирование, обобщение опыта); опросно-диагностические (анкетирование, беседа, обобщение независимых характеристик); обсервационные (прямое, косвенное, включённое наблюдение); праксиметрические (анализ деятельности студентов и преподавателей); экспериментальные (констатирующий, формирующий); количественной и качественной характеристики полученных результатов (компьютерная обработка данных, их оформление в виде таблиц, схем, рисунков).

Активная включенность студентов в занятия яхтингом способствует развитию таких значимых профессиональных качеств, как умение работать в коллективе, где важно понимание «чувства локтя»; уметь подчиняться и руководить коллективом в разных обстоятельствах; а также системного восприятия будущей профессиональной деятельности, которое способствует развитию мотивации углубления знаний в профессиональной деятельности; профессиональная самоидентификация; планирование профессиональной перспективы.

Занятия яхтингом в вузе могут быть эффективным ресурсом развития обобщённой профессиональной деятельности студентов при условии:

психолого-педагогической подготовленностью преподавателей;

- отбором средств и методов педагогического воздействия на студентов;

- личностным отношением студентов к познавательной деятельности, их собственной активностью;

- насыщения предметов блока специальных и общепрофессиональных дисциплин смыслами яхтинга;

- изменения характера содержания и организации учебных практик студентов плавательных специальностей морских вузов; организации яхтенного сообщества единомышленников, объединенного общим смыслом, возможностью осуществлять социально значимую деятельность в вузе.

Таким образом, проведенное исследование позволило в ходе констатирующего эксперимента обнаружить, что студенты, занимающиеся яхтингом в обязательном порядке, имея общее представление о хождении под парусами, не осознавали той ценности и значимости, которую предоставляют эти занятия. Кроме того, эти занятия не являлись для них профессионально значимыми. В связи с тем, что для большинства студентов была свойственна социально психологическая установка, направленная на «нигилизм», можно было констатировать, что у них отсутствовало желание и готовность полноценно и, как говорят, «с душой» заниматься яхтингом.

В ходе констатирующего эксперимента выяснилось, что знания студентов о будущей профессиональной деятельности неточны и поверхностны, не отражают всей полноты и гуманистической направленности. Важные профессионально - значимые качества 
будущего специалиста, такие как умение работать в коллективе, где важно понимание «чувства локтя»; уметь подчиняться и руководить коллективом в разных обстоятельствах; а также системного восприятия будущей профессиональной деятельности, которое способствует развитию мотивации углубления знаний в профессиональной деятельности; профессиональная самоидентификация; планирование профессиональной перспективы, развиты слабо. Диагностика этих качеств на констатирующем этапе эксперимента показала, что большинство студентов имели низкие уровни их развития.

В связи с вышесказанным необходимо так построить учебно-воспитательный процесс в вузе, который способствовал бы актуализации студентов к их профессиональной деятельности, развитию личности и побуждал их к профессиональному саморазвитию на этапе начального приобретения профессиональных навыков. [6,7].

Актуализация внутреннего мира студентов, определение ими личностной значимости и ценности занятий яхтингом стало возможным благодаря активным методам обучения. Дискуссии, круглые столы, тренинги, социальное проектирование способствовали активизации учебного процесса. Участие студентов в регатах, крейсерских походах, реализации социальнозначимых проектов, подготовке и проведении мероприятий морской направленности для различных категорий населения дало возможность студентам приобрести профессиональный и личностный опыт работы с различными категориями и типами людей, апробировать технологии работы, проявлять поддержку и взаимопомощь в реальных жизненных ситуациях. [2,4].

Изменение характера содержания и организации учебных практик дало возможность студентам активно включиться в занятия яхтингом в различных его формах, расширяя и углубляя теоретические знания студентов в практической деятельности, позволяя целенаправленно осуществлять социальнозначимую деятельность. Участие студентов в яхтенном движении запустило работу новой позитивной доминанты, направленной на преобразование их внутреннего мира и ценностных ориентаций.

Полученные в ходе эксперимента результаты подтвердили гипотезу о том, что модель студенческого яхтинга будет способствовать развитию профессиональной деятельности будущих специалистов как плавательных, так и гуманитарных специальностей, стимулировать актуализацию их личностных качеств, таких как поддержка, чувство локтя, взаимопомощь, дружба.

Для оценки эффективности занятий студентами яхтингом была разработана система критериев и эмпирических показателей, позволивших увидеть позитивную динамику изменений, происходящих со студентами, включенными в занятия под парусами, доказать условия гипотезы и убедиться в эффективности модели занятий студенческим яхтингом.

\section{Conclusion}

Выполненное исследование вносит определенный вклад в изучение проблемы личностного развития студентов, одним из ресурсов которого являются занятия яхтингом. Данная деятельность по своей природе и сущности близка профессиональной работе студентов - курсантов плавательных специальностей морских вузов и требует от ее участников проявления целеустремленности, мотивированности, самоорганизации и контроля, с принятием на себя ответственности за результат выполнения заданий.

Выделение антропоориентированного, аксиологического и деятельностного подходов в качестве методологических оснований исследования позволило определить важные положения, связанные с осознанием человека как сознательного, активно действующего участника социальных процессов, ответственного за результаты своей деятельности, как основы полноценного развития личности. [3].

Анализ философских подходов к яхтингу помог определить его педагогическую сущность. $\mathrm{OH}$ является квазипрофессиональной, общественно-полезной деятельностью и рассматривается как «антропологический, аксиологический и деятельностный ресурс» для развития у будущих специалистов нравственных ценностей и профессионально-значимых качеств, таких как как умение работать в коллективе, где важно понимание «чувства локтя»; уметь подчиняться и руководить коллективом в разных обстоятельствах; а также системного восприятия будущей профессиональной деятельности, которое способствует развитию мотивации углубления знаний в профессиональной деятельности; профессиональная самоидентификация; планирование профессиональной перспективы. Анализ психологических трудов помог выявить внутренние механизмы процесса личностного развития студентов, наиболее адекватны у занимающихся яхтингом: интериоризация, доминанта, самопознание и рефлексия. [8].

На основе философских и психологопедагогических исследований разработана 
модель занятий яхтингом в вузе. Данная модель учитывает совокупность факторов, условий, предпосылок, закономерностей и принципов профессиоанльного развития будущих студентов - специалистов, а также выявляет критерии и эмпирические показатели его эффективности.

Как показало исследование, успешность позитивного влияния яхтинга на личностное развитие студентов зависит от следующих факторов: взаимодействия преподавателей и студентов; активной включенности студентов и преподавателей в яхтинг; приобретаемого студентами позитивного субъектного опыта. $[5,10]$.

В рамках теоретического исследования выявлены педагогические условия, при которых занятия яхтингом будут являться ресурсом развития профессиональной деятельности. Таковыми являются: психодиагностика готовности студента к восприятию высшего образования и профессиональному обучению; создание рефлексивной среды, включение студентов в ситуации, требующие многовариантного решения, а также моделирующие возможные нестандартные производственные ситуации; соотнесенность учебно-профессиональной деятельности с реальной практикой профессиональной работы; использование коллективных форм деятельности, в которых благодаря групповой апперцепции происходит коррекция индивидуальных способов работы, а также усвоение профессиональных эталонов и образцов; снятие психологических барьеров у студентов при самоанализе своей учебно-профессиональной деятельности, организация переосмысления прошлого опыта; мотивационно-ценностное отношение к профессиональному выбору, адекватной личностной и профессиональной самооценки, самоконтроля и саморегуляции собственных действий и психических состояний; включение студентов в поисково-исследовательскую деятельность.

В ходе исследования было доказано, что наиболее важными предпосылками занятий яхтингом являются следующие: ценностно смысловое сходство яхтинга и профессиональной деятельности будущих студентов - специалистов морских плавательных специальностей, социальная активность студентов; наличие в вузе лидера, способного увидеть профессиональные смыслы в яхтенном движении, организовать и возглавить его.

Для выявления эффективности названных условий теоретически обоснованы и выведены следующие критерии: ценностные ориентации студентов, личностные установки, развитие профессионально важных качеств.
Анализ эмпирических данных определил конкретную связь между факторами, условиями, предпосылками личностного развития студентов и их практической деятельностью. В результате был выделен ряд существенных закономерностей: чем глубже осмысление и принятие педагогических, психологических и профессиональных смыслов яхтинга, тем выше активная включенность студентов в эту деятельность; чем шире и разнообразнее поле занятий яхтингом, тем больше у студента возможностей приобретения субъектного профессионального опыта; чем дольше пребывание студента на борту парусной яхты, тем чаще он испытывает потребность в спонтанном проявлении навыков умения работать в коллективе, умения подчиняться и руководить коллективом в разных обстоятельствах, а также системного восприятия будущей профессиональной деятельности, которое способствует развитию мотивации углубления знаний. [11].

Проведенное

экспериментальное исследование подтвердило необходимость использования ряда педагогических принципов: принцип добровольности, педагогической поддержки, педагогической преемственности.

Таким образом, теоретически обосновав модель яхтенной деятельности в вузе, важно было экспериментально проверить степень эффективности ее влияния на развитие профессиональной деятельности будущих специалистов.

Констатирующий эксперимент позволил выявить, что знания студентов о профессии поверхностны, не отражают всей глубины понимания значимости и ценности. У студентов преобладает личностная направленность и социально-психологическая установка на «нигилизм». Личностные качества характера, такие как интериоризация, доминанта, самопознание и рефлексивность развиты слабо. Результаты констатирующего эксперимента говорят о возможности организации в вузе такой среды, которая способствовала бы развитию профессиональной деятельности студентов, их готовности и потребности оказывать помощь коллегам-студентам младших курсов, побуждая их на занятия яхтингом и парусным спортом.

Опытно-экспериментальное исследование подтвердило, что наполнение предметов блока специальных и общепрофессиональных дисциплин смыслами яхтинга, а также введение спецкурса «Факультативные занятия яхтингом» и «Азбука яхтинга» для начинающих помогают студентам осознать и принять ценности яхтинга, его гуманистическую сущность; приобрести новый социальный, эмоциональный, жизненный и профессиональный 
опыт взаимодействия в различных ситуациях имитирующих будущую профессиональную деятельность.

Включая в педагогический процесс занятия яхтингом на факультативной основе, мы создаем развивающую среду, которая помогает студентам освоить новые способы поведения, изменить отношение к сверстникам, к своему образовательному учреждению, к своей стране. Яхтинг также развивает продуктивное творческое мышление, коммуникативную компетентность. Участие студентов в крейсерских походах и различных «морских» проектах помогает им приобрести опыт, связанный с организацией коллективной творческой деятельности. Это способствовало практическому проявлению и развитию таких профессионально необходимых качеств личности, как толерантность, эмпатия, рефлексивность. Проведенная работа подтверждает, что изменение характера содержания и организации учебных практик студентов углубляет и расширяет их знания в области технологии общения с различными типами личности и характера сверстников, способствует приобретению и развитию нового субъектного опыта профессиональной деятельности, формирует новую доминанту поведения и отношения к людям, нуждающихся в помощи. [13].

Проведенная опытно-экспериментальная работа доказала справедливость выдвинутых нами и теоретически обоснованных положений гипотезы.

Анализ результатов показал, что реализация всех трех педагогических условий (насыщение предметов блока специальных и общепрофессиональных дисциплин смыслами яхтинга; изменение характера содержания и организации учебных практик студентов; организация яхтенного сообщества единомышленников, объединенного общим смыслом, возможностью осуществлять социально значимую деятельность в вузе), приводит к позитивной динамике. Происходят изменения в ценностных ориентациях студентов, проявляющиеся в принятии ими социальных и личностных ценностей яхтинга, готовности и осознанной включенности в них. [12].

Позитивные изменения показателей второго критерия эффективности занятий яхтингом профессиональные установки - позволяют говорить об устойчивом интересе студентов к своей будущей профессиональной деятельности, изменении мотива этой деятельности (преобладание альтруистических мотивов), изменении смысловых, целевых установок.

Число студентов, не понимающих смысл занятий яхтингом, сокращается и увеличивается количество студентов, обладающих пониманием необходимости занятий факультативно в целях личностно - профессионального роста. У студентов старшего курса, углубленно занимающихся яхтингом, проявляется желание полноправно руководить студентами младших курсов в вопросах развития навыков управления яхтой и настройкой парусов, счисления и обсервации своего места положения и прокладкой курса на бумажных картах, что развивает их будущие профессиональные навыки руководителя и офицера торгового флота. Значительно сокращается число студентов с высоким уровнем «нигилизма».

Такие показатели критериев личностного развития студентов объясняются успешной реализацией педагогических условий, активизирующих процесс влияния яхтинга на личностное развитие будущих специалистов.

Таким образом, результаты, полученные в ходе опытно-экспериментальной работы, подтверждают, что яхтинг является одним из эффективных ресурсов развития профессиональной деятельности студентов. Следовательно, мы отмечаем, что цель исследования достигнута, задачи выполнены.

Исследование не претендует на окончательное решение проблемы поиска путей и средств, способствующих личностному развитию студентов, но актуализирует проблему подготовки специалиста, используя для этого ресурс занятий яхтингом в вузе. Дальнейшее углубленное исследование данной проблемы может осуществляться в направлении изучения влияния яхтинга на студентов, обучающихся по специальностям гуманитарного профиля.

Возможен научный поиск, направленный на разработку проблемы воспитания школьников, студенческой молодежи средних и специальных учебных заведений, а также учащихся профтехобразования по вовлечению их в занятия яхтингом, формированию у них активной гражданской позиции, любви к своему учебному заведению, к своей стране. 


\begin{tabular}{l|lr|ll|ll} 
& ISRA (India) & $=\mathbf{1 . 3 4 4}$ & SIS (USA) & $=\mathbf{0 . 9 1 2}$ & ICV (Poland) & $=\mathbf{6 . 6 3 0}$ \\
Impact Factor: & ISI (Dubai, UAE) $=\mathbf{0 . 8 2 9}$ & PUHL (Russia) $=\mathbf{0 . 2 3 4}$ & PIF (India) & $=\mathbf{1 . 9 4 0}$ \\
& GIIF (Australia) & $=\mathbf{0 . 5 6 4}$ & ESJI (KZ) & $=3.860$ & IBI (India) & $=\mathbf{4 . 2 6 0}$ \\
& JIF & $=\mathbf{1 . 5 0 0}$ & SJIF (Morocco) & $=2.031$ & & \\
\hline
\end{tabular}

\section{References:}

1. A.N. Leontev (1975) Deyatelnost. Soznanie. Lichnost. M.: Politizdat, $1975-130$ p.

2. L.S. Vygotskij (1934) Myshhlenie i rech. M.L.: Socekgiz,1934 - 323 p.

3. P.Ya. Galperin (1999) Vvedenie v psixologiyu. M.: Knizhnyj dom «Universitet», 1999 - 150 p.

4. Z.A. Reshetova (1985) Psixologicheskie osnovy professionalnogo obucheniya. M.: Iz-vo MGU, $1985-207$ p.

5. N.F.Talyzina (1998) Pedagogicheskaya psixologiya. M.: Akademiya, 1998 - 288 p.

6. V.V. Davydov (1992) Psixologicheskaya teoriya uchebnoj deyatelnosti i metodov nachalnogo obucheniya, osnovannyx na soderzhatelnom obobshhenii. T.: Peleng, 1992 $113 \mathrm{p}$.

7. I.I. Ilyasov (1981) Organizaciya sovmestnoj raboty studentov. (v soavt.). M.: $1981-145$ p.

8. O.K. Tixomirov (1975) Psixologicheskie issledovaniya tvorcheskoj deyatelnosti. M.: Nauka, 1975 - 252 p.

9. A.G. Asmolov (1984) Lichnost kak predmet psixologicheskogo issledovaniya. M.: Iz-vo MGU, 1984 - 104 p.
10. Samonenko Yu.A. (2001) Psixologiya i pedagogika. M.: Yuniti-Dana, $2001-277$ p.

11. Mishchik S.A. (2015) Pedagogometrik - science and academic subject. Materialy Mezhdunarodnoy nauchnoy konferenctsii "European Technology in Science" 28.02.2015. ISJ Theoretical \& Applied Science 02 (22): 103-106 Malmö, Sweden. doi: http://dx.doi.org/10.15863/TAS.2015.02.22.17

12. Medvedev V.N. (2017) Yachting - is the factor of development of social activity of students. Materialy Mezhdunarodnoy nauchnoy konferenctsii "Technology and Education" 30.06.2017. ISJ Theoretical \& Applied Science 06 (50): 133-138. Philadelphia, USA. doi: https://dx.doi.org/10.15863/TAS.2017.06.50.18

13. Medvedev V.N. (2017) Yachting - the condition of forming of the identity of the student. Materialy Mezhdunarodnoy nauchnoy konferenctsii "Materials and Technologies" 30.07.2017. ISJ Theoretical \& Applied Science $07 \quad$ (51): 117-122. doi: https://dx.doi.org/10.15863/TAS.2017.07.51.20 